\title{
Spanish non-continuants at the phonology-phonetics interface*
}

\author{
Karolina Broś \\ University of Warsaw \\ k.bros@uw.edu.pl
}

Received: 14-04-2017

Accepted: 21-08-2017

\begin{abstract}
This paper takes a series of lenition phenomena from Gran Canarian Spanish as a point of departure to discuss the influence of phonology on the phonetics component. Based on phonetic and phonological data, it can be concluded that a blocking effect ensues between the process of coda deletion and post-vocalic voicing, giving rise to phonetic opacity. Against the assumption that the latter process is phonological in nature, acous-tic data suggest that it is highly gradient, coarticulatory and variable, in which case it is inexplicable why it is blocked by phonological segment deletion. The proposed solution set forth in this paper is that the phonetic component has access to deep structure beyond featural specifications of sounds. What is more, evidence from prosody indicates that structural information concerning prosodic boundaries is also transposed into phonetics and influences production. Thus, the type and amount of information computed at the phonetics-phonology interface needs to be revised and supplemented by turbid structures in order to account for surface variability and both inter- and intra-speaker differences.
\end{abstract}

Keywords: postvocalic voicing, Gran Canaria, Spanish lenition, turbidity

\section{Table of Contents}

1. Introduction

2. The data

\section{Gradiency and intra-speaker variation}

4. Voicing and prosody

5. Voicing and turbidity

6. Conclusions

${ }^{*}$ This paper is a result of fieldwork and phonetic experiments conducted in February and JulyAugust of 2016 in Gran Canaria. I would like to thank all the speakers that agreed to participate in these studies, especially Jesael Jorge Sosa. I also thank Joanna Zaleska for her invaluable support and technical advice. Finally, I would like to express my gratitude to the two anonymous reviewers of Isogloss for their useful comments and criticism, which definitely helped improve the paper. However, let me add that the responsibility for this article is solely mine. 


\section{Introduction}

The Spanish of Gran Canaria has been reported to have post-vocalic voicing (/p t k t $\int / \rightarrow$ [b d g d $]$ ]) both inside words and across word boundaries (Broś, 2016b; Oftedal, 1985). At the same time, it exhibits spirantisation which turns voiced stops into approximants of differing strength (aperture) after continuant sounds. The two changes have partially overlapping environments, which seems to produce a synchronic chain shift effect. ${ }^{1}$ They also differ in their sensitivity to edge effects in preceding words. Whereas spirantisation applies regardless of segmental changes taking place in the immediate left-hand environment, voicing is categorically blocked. More specifically, whenever a word-final consonant is deleted in the preceding word, voicing does not apply despite the fact that the segment in question is preceded by a vowel as a result. ${ }^{2}$ Thus, although the process of voicing is widely extended and productive across speakers, and assigned at the level of continuous speech where syntactic phrases have been built, it is blocked whenever the preceding segmental material is deleted in the course of phonology. Given these observations, it can be concluded that both post-vocalic voicing and coda elision are connected speech phenomena that belong to the phonological component. Phrase-level phonology has to deal with cases of voicing inhibition due to deletion.

A recent phonetic study, however, challenges this assumption. The data gathered in the course of an experiment conducted among 20 native speakers suggest that the process of post-vocalic voicing is highly coarticulatory and phonetic rather than phonological. First, it appears that the change is gradient. Second, there are differences in the degrees and frequency of voicing depending on the sound. Third, inter- and intra-speaker variation can be observed. Other phonetic features, such as variable lack of plosion and approximantisation, should also be taken into account as markers of variability and noncategoricity of the observed phenomenon. All in all, given these facts, it is difficult to explain why the apparently phonetic process of voicing does not take place in segments following elided consonants. Since voicing is gradient and highly dependent on the phonetic makeup of the immediate context, it is expected that in deletion environments, voice spilling should easily take place from the preceding vowel, yet this assumption is not borne out.

The aim of this paper is to provide phonetic evidence of the discussed processes and blocking effects, and to present a formal analysis of how the correct surface forms are generated. Crucially, I argue that structural elements erected at the level of phonology must be phonetically interpretable alongside segmental information. In other words, deleted segments must leave a trace in the surface representation that is visible postphonologically. What is more, elements marking prosodic boundaries must also be transposed as they modulate the occurrence and degree of segmental changes. The data provided in this paper show that the phonetic component is able to detect and interpret the language of phonological computation beyond melody and phonetic features. As a result, opacity in the form of underapplication ensues. Such an interpretation of the facts requires

1 See formal analyses of these facts provided by (Broś, 2016a, 2016b; Gussenhoven and Jacobs, 2011).

2 For instance, po(r) pensa(r) tontería(s) 'for thinking about silly things' cannot be realised as *[po.ben.sa.don.te.rí.a]. It is opaquely produced without voicing: [po.pen.sa.ton.te.rí.a]. See (9) and the discussion in the next section for details. 
two principal assumptions: (1) the dichotomy between melodic and structural information in phonology (the two tiers are both representationally and functionally independent), and (2) turbid structures and the resultant mediation between projection and pronunciation, in which the latter gives a direct link to phonetic interpretation and a rationale for deep structure visibility at the production stage.

The paper is structured as follows. Section 2 presents the data from Gran Canarian Spanish. Section 3 summarises the phonetic experiment and fieldwork data that serve as the basis for the assumptions signalled above. Section 4 discusses the role of prosody in the observed variability of voicing, while Section 5 provides a formal analysis of the data couched in the Turbid Optimality Theory framework. General conclusions are set forth in Section 6.

\section{The data}

As indicated in the introduction, in the northern part of Gran Canaria, Spain, an extended process of non-continuant voicing can be observed (1). The process is accompanied by generalised Spanish spirantisation, (2), which turns voiced stops into approximants of differing strengths (apertures). The contexts of occurrence of the two processes partially overlap, creating a chain effect. The data illustrating the two processes are presented below, as reported by Oftedal (1985), and recently by Broś (2016b).

$$
\text { Voicing }
$$

/p/ de[b]artamento 'department' /t/ fone[d]ica 'phonetics'

/k/ má[g]ina 'machine' /tf/ le[d] ' 'milk'

\section{/p/ yo [b]ienso 'I think'}

/t/ juntos y [d]al 'together etc.'

/k/ de [g]olombia 'of Colombia'

/t $\mathrm{j} / \mathrm{la}[\mathrm{d}]$ ]ica 'the girl'
(2) Spirantisation

$$
\begin{aligned}
& \text { /b/ lle }[\beta] \mathrm{o} \text { 'I take' } \\
& \text { /d/ po[ðָ]er 'be able to' } \\
& \text { /g/ ma[§] ]o 'magician' }
\end{aligned}
$$

$$
\begin{aligned}
& \text { /b/ la }[\beta] \text { oca 'the mouth' } \\
& \text { /d/ una [ðָ] osis 'one dose' } \\
& \text { /g/ mi [ð]]rupo 'my group' }
\end{aligned}
$$

In (1), it can be observed that voiceless sounds undergo voicing in intervocalic position both inside words and across word boundaries, whereas in (2) we can see that voiced stops turn into approximants in the same context. ${ }^{3}$ It must be noted, however, that approximants are produced also after any other [+continuant] sound, although with different degrees of aperture (4); whereas voicing applies strictly in post-vocalic position, regardless of what is found to the right of the target segment. Other consonants block the process, as shown in (3).

$3 \quad$ As mentioned in the introduction, voicing also encompasses the voiceless palatal affricate $/ \mathrm{t} J /$. There is no voiced counterpart of this sound in the Spanish phonemic inventory, hence the asymmetry. Spirantisation is irrelevant for the palatal place of articulation. 


$$
\text { Voicing is blocked }
$$

el [t]riple 'three times' súper [k]ómodo 'very comfortable' las [k]asas 'the houses' el [t $f]$ isme 'the gossip'

\section{Spirantisation is not blocked}

el $[\beta]$ uque 'the ship' súper [§] $]$ or[ðָ]o 'really fat' las $[\mathrm{y}]$ otas 'the drops'

Both processes are blocked by homorganic non-continuants (nasals and [1] in the case of the dental stop series); this is illustrated below.

\section{Voicing is blocked}

im[p]ortante 'important'

en[t]onces 'then/so'

un ban[k]o 'a bench'

los guan[t]]es 'Guanche people'
(6) Spirantisation is blocked

in[b]olucrado 'involved' en[d]oso 'endorsement'

el Con[g]o 'Congo'

Each of the processes can be classified as an instance of lenition, i.e. spontaneous sound weakening leading to feature loss and less 'consonantal' pronunciations. Interestingly, they produce a phonemic overlap (Bloch, 1941): voiced stops can be allophones of both voiceless and voiced underlying stops. Given the fact that the two changes apply in partially overlapping contexts, full neutralisation is impeded, but but the resultant contrasts are admittedlly not very robust. In the majority of the cases, we are dealing with a weak voiced stop - approximant contrast which is not very salient in perceptual terms. Minimal pairs produced by this grammar can be problematic from the point of view of speech comprehension (see 7 and 8), and lead to further stages of language change, e.g. to maintaining or enhancing contrast. ${ }^{4}$

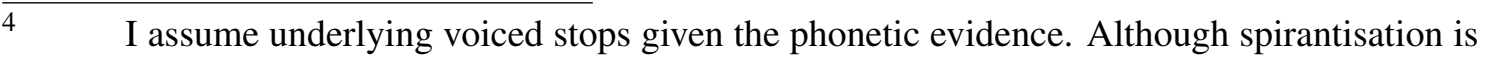
widespread and exceptionless across speakers, there are differences in the degree of aperture in 'underlying' voiced stops depending on the preceding sound. More specifically, intervocalic stops inside words are often barely audible and merge with vowels. Across word boundaries, they also tend to be very weak, with small VCV formant transitions. After liquids, they tend to be more consonantal, although they do show formants; whereas they are the least open after other consonants, e.g. /s/ weakened to [h]. What is more, as will be mentioned later in this section, voiced stops following deleted consonants are also weakened to a lesser extent than in underlyingly intervocalic contexts. Given these gradient differences in production, I conclude that various degrees of weakening affect underlying voiced stops in Gran Canarian rather than underlying approximants, whose exact aperture cannot be determined at the level of the UR and which are additionally hardened to stops in absolute initial and post-nasal position. Nevertheless, see e.g. Baković (1995) for arguments for positing underlying approximants in Spanish. 


\section{Results of voicing}

la cama [lagáma] 'the bed' cuatro [kwádro] 'four' la poca [labóka] 'the little'

\section{Results of spirantisation}

la gama [layáma] 'the range' cuadro [kwádro] 'painting'

la boca [laßóka] 'the mouth'

Thus, the leniting changes observed in the dialect are gradual in the sense that only one feature is affected. In voicing, the laryngeal specification, or feature [voice], is involved, whereas in spirantisation, a [-continuant] sound becomes [+continuant]. The two features cannot be affected simultaneously in the same token. In a phonological analysis, feature faithfulness must be sacrificed to satisfy the constraint(s) demanding weakening, yet the violation must be minimal. Voiceless segments do not go as far as to become approximants. This is best explained by applying an order of events: voicing must apply second to counterfeed spirantisation.

Apart from the chain shift effect caused by the application of two processes affecting non-continuants in overlapping environments, another case of underapplication can be observed in the Gran Canarian dialect. Of interest here is the interaction between the two consonantal changes described above and another lenition process: coda elision. As illustrated in (9), coda consonants are optionally deleted in spontaneous speech. The process is easiest to observe in the case of $/ \mathrm{r} /$. In underlying $/ \mathrm{s} /$, debuccalisation to [h] usually ensues and the resultant glottal fricative can be weakened to varying degrees or dropped altogether, usually at the end of a word, provided that the following word starts with a consonant. If the following word begins with a vowel, resyllabification of the debuccalised /s/ takes place opaquely, similarly to Caribbean and South American dialects of Spanish (Broś, 2015; Colina, 1997; Kaisse, 1999; Lipski, 1996; Wiltshire, 2002).

\section{Deletion and voicing in interaction (Broś, 2016a)}

$\begin{array}{lll}\text { la(s) caracterí(s)tica(s) } & \text { [la.ka.rak.te.rín.ti.ga] } & \text { 'the features' } \\ \text { die(z) primo(s) } & \text { [dje.prí.mo] } & \text { 'ten cousins' } \\ \text { por pensa(r) tontería(s) } & \text { [por.pen.sá.ton.te.rí.a] } & \text { 'for thinking about silly things' } \\ \text { se puede acepta(r) que } & \text { [se.pwé.ðָe.a.sep.tá.ke] } & \text { 'it can be accepted that' }\end{array}$

As illustrated in (9), coda consonants can undergo elision, which should feed voicing. Nevertheless, the latter process fails to apply despite the fact that the stop following the deleted segment becomes post-vocalic. ${ }^{5}$ Thus, we are facing a blocking effect that cannot

$5 \quad$ Note that coda elision affects weakened $/ \mathrm{s} /$ and $/ \mathrm{r} /$. Further research is necessary to see whether this extends to $/ 1 /$, which appears word-finally only rarely. I have not heard or seen deletion of this sound, which may be due either to its specification for continuancy (Mascaró, 1991) or to the fact that it rarely appears at the end of a word and usually only in object denoting nouns. By contrast, $/ \mathrm{r} /$ and $/ \mathrm{s} /$ appear in grammatical items and frequently occuring words and morphemes, such as infinitive verb endings, plural nouns and adjective endings, plural conjugations, etc. It must be noted, however, that mentions of both $/ \mathrm{r} /$ and /l/ deletion have been made in the literature for southern Spanish varieties and some parts of Canary Islands, and /1/ deletion has been reported in e.g. Cuba and Panama. See an overview of these issues in Hualde, Olarrea, and O'Rourke (2012). Interestingly, 
be explained in surface-based terms. The lack of voicing is opaque. This observation becomes all the more relevant when faced with the fact that spirantisation is not blocked by coda elision, as shown in (10).

\section{Deletion and spirantisation in interaction}

\begin{tabular}{|c|c|c|}
\hline (s) gato(s) & [lo.ya.to] & 'the cats' \\
\hline & & y day’ \\
\hline $\begin{array}{l}\text { no(s) de todo } \\
\text { (r) do(s) cosa(s) }\end{array}$ & 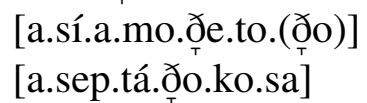 & 'accept two things' \\
\hline
\end{tabular}

As illustrated in (10), spirantisation is not blocked by deletion, as opposed to voicing. It must be noted, however, that the degree of approximantisation in deletion contexts is not as high as in the case of underlyingly intervocalic voiced stops. Rather, these segments are only 'mildly' approximantised, quite similar to those voiced stops which follow consonants across word boundaries. It is worth mentioning that intervocalic voiced stops lose their consonantal properties totally (elision) or almost totally (weak approximants with clear formants and very slight formant transitions on the boundary with either of the vowels) in fast speech. To illustrate the differences between voiced and voiceless stop productions in deletion contexts, the relevant spectrograms have been annotated and presented in Figures 1 and $2 .^{6}$

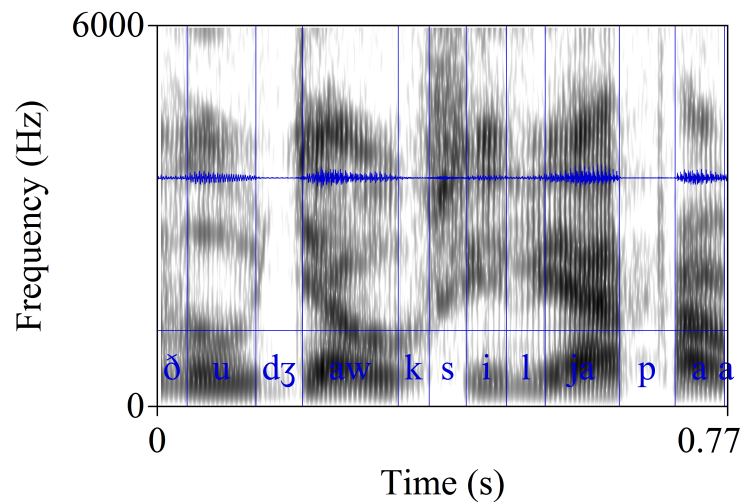

(a) ducha auxiliar para 'additional shower for'

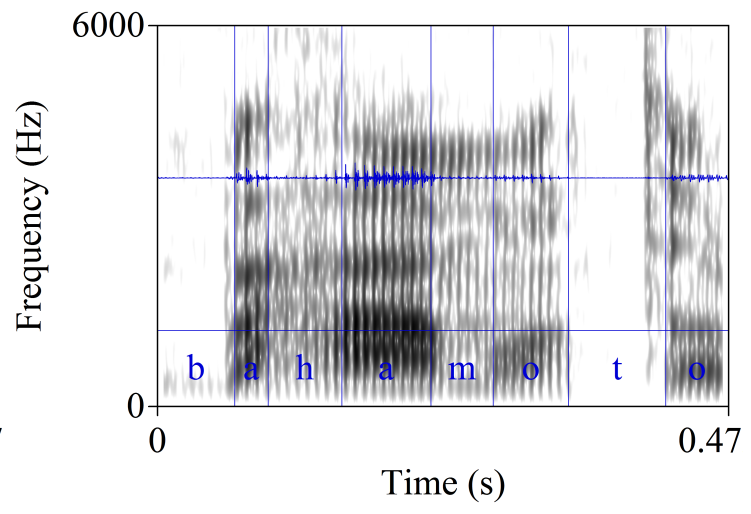

(b) bajamos todos 'we all went down'

Figure 1: Voicing is blocked by deletion

weakened consonants that never surface as stops word-finally, such as /d/ in e.g. libertad 'liberty' or Madrid are either lenited to weak approximants or dropped. The latter word can therefore surface as [ma.ðrí̛⿱]] or [ma.ðrí]. This could be used as an argument for a stratal analysis in which segments are first weakened and only then elided completely, in line with McCarthy (2008). Nasals are never dropped, although they are debuccalised word-finally, with resyllabification before vowel-initial words. phrase was produced spontaneously by a 24-year-old native speaker of Gáldar, Gran Canaria during an extended interview. Other speakers present similar features. 
As shown in Figure 1, no voicing occurs after the vowel [o] of the word bajamos in which the final $s$ is not pronounced despite the fact that the following [t] is apparently post-vocalic. ${ }^{7}$ The same applies to the second example in which $r$ is deleted, but the [p] remains unvoiced despite being preceded by a vowel. The two cases can be contrasted with phrases presented in Figure 2 where the voiced stop is weakly spirantised in deletion

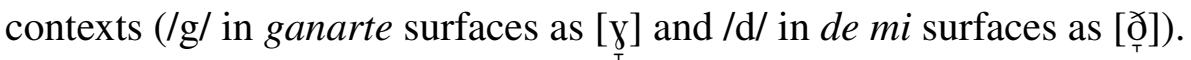

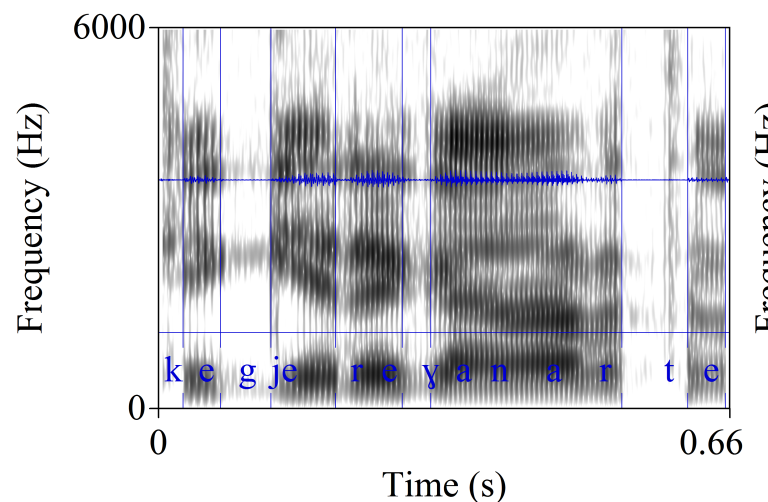

(a) que quieres ganarte 'that you want to earn'

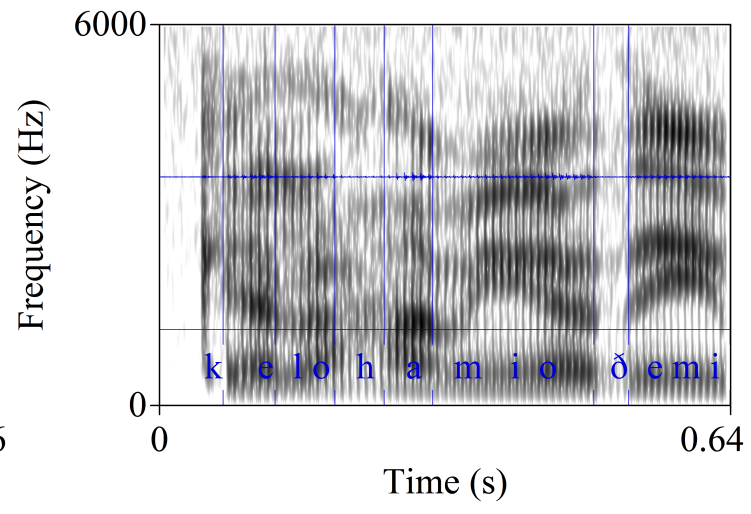

(b) que los amigos de mi... 'that my ...'s friends'

Figure 2: Spirantisation is not blocked by deletion

Additionally, note that the /g/ in amigos 'friends' is elided and the voiceless stops that are underlyingly intervocalic present voicing (quieres 'you want'). ${ }^{8}$ Thus, we can conclude that deletion selectively acts as a blocker in Gran Canarian Spanish. The interim conclusion based on these data is that the deleted segment must be somehow visible or structurally present and thus the following stop is not truly intervocalic from the phonological point of view. Consequently, voicing cannot apply. This is of no relevance for spirantisation, which applies after continuant consonants anyway. Note that the consonants that are deleted in the dialect are typically $r$ and $s$, hence continuants.

$7 \quad$ Note that the second word is clipped to [to]. This is how the speaker produced the word in a continuous speech string. Intervocalic voiced stops are very often elided in rapid speech and the resultant vowel sequence merges into one short or long vowel, depending on the speech rate.

The fact that there are such differences in the production of voiced stops depending on the position in the word and on the left-hand context is worth examining, but requires further study. More specifically, a quantitative analysis of the different productions across speakers should be provided in order to draw appropriate conclusions concerning the degrees of spirantisation in the dialect and its phonological status. The preliminary analysis of the acoustic data shows that there is a difference between intervocalic voiced stops and voiced stops following other continuants or (apparently) deleted segments in this dialect, which could lead to the hypothesis that deletion does affect the process of spirantisation to some extent. Nevertheless, such a claim would have to be confirmed by different behaviour of voiced stops following pronounced consonants as opposed to following deleted consonants. At this point, such evidence cannot be put forward. 
The interaction of the three processes suggests that they all belong to the phonological component. What is more, they can affect segments in word-internal position and at word edges. Each of them is also sensitive to syntax to some extent (spirantisation and voicing in word-initial position depend on the left-hand environment, i.e. previous word, whereas deletion can be blocked by resyllabification if the following word starts with a vowel). In formal terms, a precedence relation would have to be established in order to account for the surface forms presented in this section.

Spirantisation is the least problematic. It can apply at any time with respect to deletion as it is apparently not blocked by it, nor is it blocked by the presence of a coda consonant, as long as the latter is a continuant. To ensure that voicing is blocked, however, we should order it before deletion. Otherwise, the lack of voicing is inexplicable on the surface. In terms of Optimality Theory (Prince and Smolensky, 1993), these facts cannot be captured correctly unless we assume a stratal approach (Bermúdez-Otero, forthcoming). As will be argued in Section 5, however, the division of the grammar into morpho-phonological strata does not grant a correct analysis. Note that the three processes analysed here have similar structural descriptions and domains of application. They also belong to the general category of lenition phenomena. There is no reason to posit them at different strata. Hence, given their word-internal activity, they may be assigned to the word level and remain active at the phrase level (the relevant constraints are not reranked) or they may be activated at the phrase level. If these processes are active simultaneously within a given stratum, however, opacity ensues and it is impossible to derive the correct output forms (i.e. with deletion and spirantisation, but not voicing). This issue will be addressed further in Section 5. In the meantime, let us turn to yet another complicating factor: phonetic variation.

\section{Gradiency and intra-speaker variation}

Although the process of post-vocalic voicing has been referred to as a generalised consonantal change presented by the native speakers of Gran Canarian Spanish (Gussenhoven and Jacobs, 2011; Oftedal, 1985) and despite the fact that it is produced quite systematically across the two sexes by both young and old speakers in spontaneus productions (Broś, 2016b), it appears not to be so consistent in a controlled setting. A phonetic study conducted by Broś (to appear) challenges the assumption that voicing forms part of the phonological component. The data gathered in the course of an experiment conducted among 20 native speakers suggest that the process of post-vocalic voicing is highly coarticulatory and phonetic rather than phonological.

The study consisted of 98 audio stimuli presented to the participants in two versions (with and without voicing) and reproduced by them in a controlled setting. All the four places of articulation were probed ([p t k t $f]$ ). The stimuli were embedded in a carrier sentence He comprado cinco 'I have bought five'. After the numeral, a noun phrase beginning with one of the tested sounds was provided. Sample sentences are provided in (11).

\section{(11) Sample stimuli with voicing targets to the right of the numeral}

He comprado cinco panes de millo 'I have bought five corn breads' 
He comprado cinco tarros de garbanzos 'I have bought five cans of chickpeas' He comprado cinco cubos de basura 'I have bought five trash bins'

He comprado cinco chochos de yema 'I have bought five yolk candies'

The aim of the experiment was to measure voicing frequencies and sensitivity to the voicing of the input. It was assumed that the process would be systematic and categorical, and that no substantial differences would occur between the voicing rates of each of the probed sounds. Contrary to the expectations, the study revealed that there was substantial variability in the produced outputs. Both inter- and intra-speaker variation was observed. The average voicing rate of the target sounds was merely $45 \%$, with substantial differences between the two sexes (29\% in females vs. $59 \%$ in males). ${ }^{9}$ What is more, voicing was gradient. Full voicing was produced in $29.5 \%$ of the cases, whereas partial voicing occurred in $15.4 \%$ of the outputs. It must be noted, however, that a rigorous classification was used based on the acoustic data. Given the fact that vowels tend to leave a substantial voicing trail in the dialect, it was decided that the 'safe' threshold for deeming a given segment partially voiced was when there were glottal pulses and voicing was visible on the voicing bar in Praat (Boersma and Weenink, 2015) in more than 50\% of the sound duration. Full voicing was annotated when the whole of the sound, including release, was voiced. There were, however, numerous cases of slight voicing which were not counted as either category as they did not fulfill these requirements. Hence, voicing in the dialect does not always occur in connected speech, and if it does, it is definitely not categorical.

Another interesting observation was the lack of plosion. Some voiced items were produced without a burst, while others had more 'typical' plosive pronunciations. In some cases, formants could be observed, suggesting approximantisation, but this mainly involved $/ \mathrm{k} /$, a plosive which is the least natural candidate for voicing from the articulatory point of view (Johnson, 1997; Ohala, 1983). As for the place of articulation, the difference in voicing was quite noticeable in the case of $/ \mathrm{t} f /$ when compared between the sexes. Otherwise, /p/ was the most frequently voiced consonant. Some examples of variation in terms of voicing degree and consonant release are presented in Figures 3 and 4.

$9 \quad$ This effect has not been previously reported to the best of my knowledge. The hypothesised reason for this discrepancy, according to (ibid.) is sociolinguistic, and more precisely, has to do with Labov's gender paradox (Labov, 1990). 


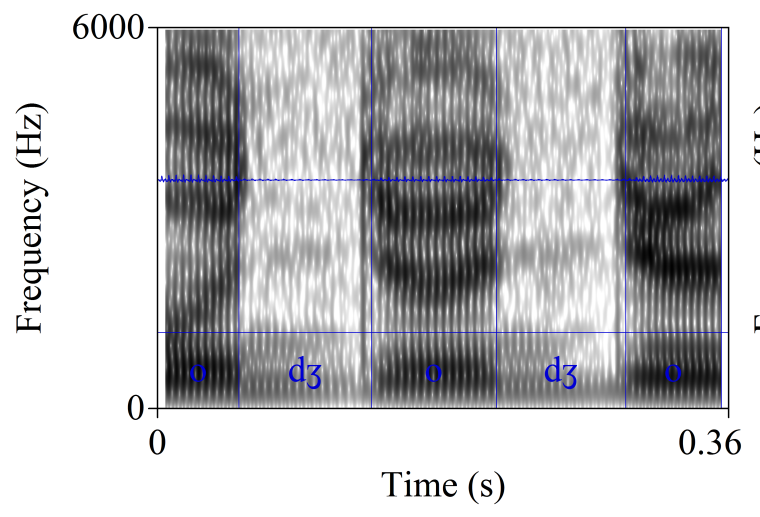

(a) chochos 'candies'

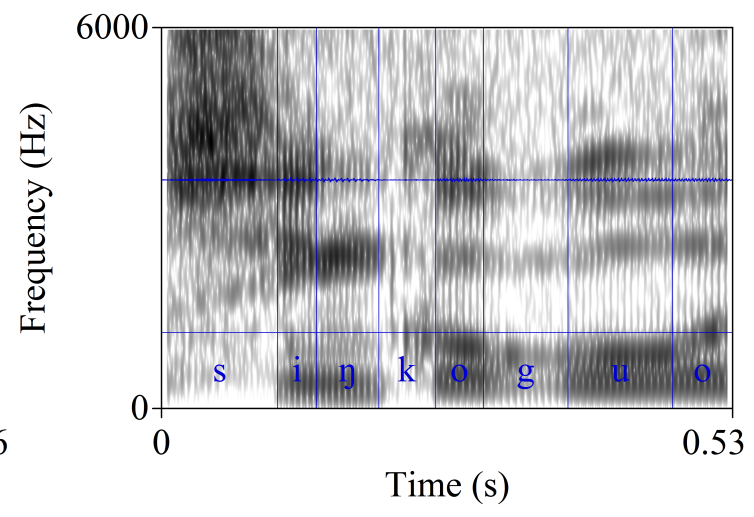

(b) (cinco) cubos '(five) bins'

Figure 3: Full voicing with release in chochos 'candies' (a); no release and formants in voiced / $\mathrm{k} /$ in cubos 'bins' (b).

In Figure 3, we can observe that in (a) both palatal non-continuants are voiced. The first one is perhaps not fully voiced, but rather $95 \%$. Both consonants are preceded by the vowel [o]. In the case of (b), we can see not only full voicing of the $/ \mathrm{k} /$, but also lack of plosion and formants.

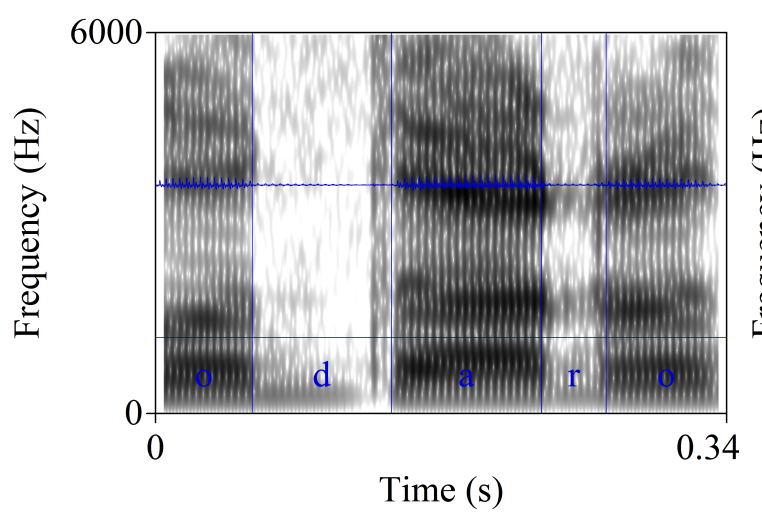

(a) tarros 'jars'

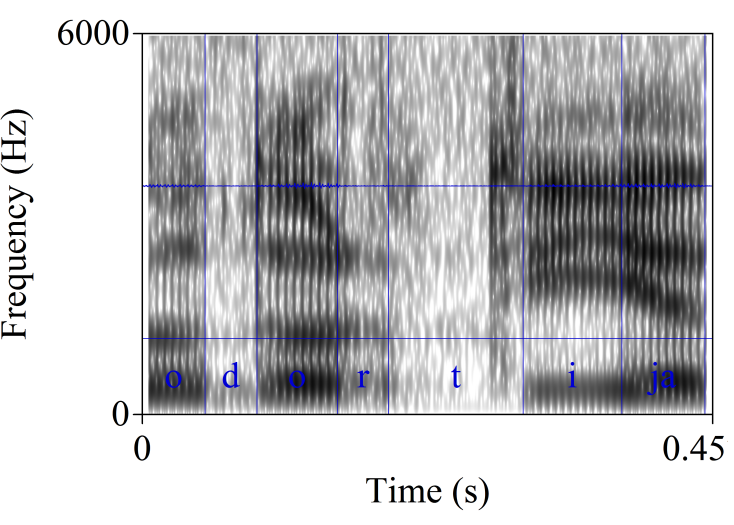

(b) tortillas 'omelettes'

Figure 4: Partially voiced /t/ with a burst in tarros 'jars' (a); voiced /t/, no visible burst vs. unvoiced second /t/ in tortillas 'omelettes' (b).

In Figure 4, we can observe partial voicing of /t/ in the word tarros 'jars' in (a). As observed on the voicing bar, pulses do not continue throughout the sound - there is a break shortly before the release of the stop. In (b), we have two underlying / $t$ / sounds, one of which is post-vocalic, hence undergoes voicing. There is some noise, but no clear burst. The second /t/ is post-consonantal and therefore unvoiced. A clear burst can be observed in this case.

Given the results of the experiment, I assume that voicing is an ongoing language change affecting voiceless non-continuants in Gran Canarian Spanish. Although it is 
possible that it will pass to the phonological component at some point, it has not been established as a categorical process to date. I will therefore analyse it as a gradient phonetic phenomenon that is highly reliant on coarticulation.

In view of these characteristics of voicing, it remains unclear why it fails to apply in deletion contexts. After all, under the assumption of modularity, once a word or phrase leaves the phonological component, all internal information concerning the underlying representation and previous stages of derivation is lost. The phonetic implementation component is not supposed to have insight into the workings of phonology. It is to rely on the output form only. If the final /s/ in las 'the' is deleted before the word características 'features', the output form subject to phonetic implementation is /la.ka.rak.te.rín tit.ka/, i.e. a form in which there are two voiceless stops preceded by a vowel. Yet only the second one shows voicing ([la.ka.rak.te.rí ${ }^{\mathrm{h}}$.ti.ga]).

If voicing is not a phonological process, as the acoustic data suggest, then the only other option is to assume that some remnants of structural information from phonology are visible to phonetics. What is phonetically interpretable is non-melodic, structural information, such as syllable structure, phrasing and other prosodic data. I assume that despite being unpronounced, segmental nodes present at the level of the UR are projected and remain in place throughout speech processing, including articulation. In this way, the overlap of articulatory gestures is inhibited and voice spilling across sonorants does not take place. In psychological terms, this can be explained as follows. The intention of producing a given sound is there but it is not realised in online processing for some reason (effort reduction, physical limitations of the vocal tract, undershoot). If there are too many gestural transitions to make in a short period of time, reduction can take place to facilitate pronunciation, especially when the meaning of the resultant speech forms is not lost (in predictable environments, such as plurals and verbal endings). A slightly different explanation can be sought in gestural masking by which two gestures responsible for different articulatory areas or targets (and corresponding to two different tiers) may mask each other when they coincide, the effect being perceptual blending (Browman and Goldstein, 1990). The resultant sound may be technically there (the corresponding gesture is effected) but perceptually absent (unpronounced). In acoustic terms, there is no remnant of the deleted segment in Gran Canarian Spanish, however. The speech signal clearly shows that there is no sound, hence it cannot be heard. Nevertheless, it cannot be stated for sure whether the corresponding gesture occurs as this would require an electropalatographic study.

With the above facts in mind, I conclude that deletion is a categorical phonological process and must be accommodated in the phonological component. If articulation, which is modulated by the information processed in the phonetic implementation, is guided by structural and featural data provided by the phonology, it must be assumed that deleted consonants act as blockers in the phonetics. Despite being stripped of featural information concerning melody, the root node must remain in place, possibly also marking a syllable boundary. From the formal perspective, such a view of the events extends the turbidity approach represented by e.g. Goldrick (1998) to the phonetic implementation, or to the phonology-phonetics interface. This solution is further discussed in Section 5.

What remains to be explored is the rationale behind variability in the production of voicing. 


\section{Voicing and prosody}

A closer examination of the acoustic data leads to a possible alternative explanation of the interaction between deletion and the blocking of voicing that has to do with the phonology-phonetics interface. ${ }^{10}$ The phonetic material gathered in the course of the experiment presented by Broś (to appear) suggests that fast speech rate and lack of physical pauses do not necessarily imply voicing. There were scarcely any cases of hesitation or breaks in the speech signal between the introductory phrase and the stimulus. Yet despite there being continuous speech, voicing occurred variably and with differing strength, both within and across speakers.

It must be mentioned that the carrier phrases were structured as follows: Auxiliary + Verb + Numeral + Noun + Preposition + Noun. The target word was always a noun following the numeral cinco 'five'. From the point of view of Spanish prosody, such a structure is appropriate as an experimental condition as nouns are typically phrased together with the preceding numerals (Mercedes Cabrera Abreu, p.c., cf. Cabrera Abreu and Vizcaino Ortega 2010, Prieto, 2007). Nevertheless, the resultant structure is quite long and complex. What is more, a stronger relation ensues between the constituents of the NP beginning with the target word (always a container or an object made up of other objects) than between the numeral and the target word which, together, form a Quantifier Phrase (QP). According to Cabrera Abreu (p.c.), it is possible for speakers to make an intonational break between the numeral and the following NP without marking it with a pause, e.g. in a reading task, if they want to make sure that they pronounce the following word correctly. This could take the form of a continuation rise in the pitch contour. Although the experiment discussed here did not involve a reading task, an intonational break is not unfathomable given that the participants had to 'make sure' they reproduce or remember the word from the audio stimulus correctly. In the absence of independent psycholinguistic or neurolinguistic data on this retrieval process, such a possibility should be entertained. This is especially so because, even though stops outside of the target word were not the subject of the experiment, it was noted that speakers would voice the $/ \mathrm{k} /$ of comprado 'bought' and the stops following the target sound (i.e. the first sound of the word following cinco 'five'), but not the target sound itself on many occasions. This presence/absence of voicing may be due to sensitivity to prosodic boundaries.

In line with the tenets of prosodic phonology (Nespor and Vogel, 1986; Selkirk, 1986), prosodic structure is hierarchical and typically represented as starting from the smallest unit, the syllable, and going upwards to bigger constituents, as illustrated in (12). Each of the resultant tiers is erected during speech processing, in phonology, and then at the phonology-syntax interface.

10 I assume that prosody, which is the topic of this section, is primarily phonological. Crucially, it defines suprasegmental structures which serve as domains of application of phonological processes. Nevertheless, the phonetic dimension of prosody cannot be denied, as its very expression has to do with a series of acoustic cues. Moreover, prosody is known to at least partially depend on syntax and to be linked to the pragmatics of speech production. In general, therefore, prosody is best defined as an interface structure erected at the level of phonological computation and modulated by other components of the grammar. 


\title{
Prosodic structure
}

\author{
syllable $(\sigma)$ \\ foot $(\mathrm{F})$ \\ prosodic word (PW) \\ phonological phrase (PPh, Minor Phrase) \\ intonational phrase (IP, Major Phrase)
}

Like other Romance languages, Spanish shows sensitivity to Minor Phrase boundaries. First, a main stress (accent) is typically placed on the last tonic syllable of a Minor Phrase (Prieto, 2007; Quilis, 1993). Second, there is optional tonal marking (continuation rise) in this environment. Several studies demonstrate that the presence of intermediate boundaries can help disambiguate speech in this language (Hualde, 2002; Nibert, 2000). Given these facts and the structure of the test sentences used in Broś' experiment, it is possible that a minor prosodic unit is erected by the speakers between the numeral and the following NP that causes changes in the pronunciation of the sounds occurring at the edges, e.g. lack of voicing or a lesser degree thereof. Empirical support for this hypothesis comes from several sources.

Elordieta, Frota, and Vigário (2005) provide evidence for Spanish speakers' preference to phrase SVO structures as (S)(VO) rather than (SVO), as opposed to e.g. the Portuguese. They also point to the weight of the prosodic constituent and branchingness as major factors influencing phrasing in continuous speech. In a different study, Prieto (2007) provides evidence from Peninsular Spanish for the fact that speakers are guided by prosodic constraints and not only the syntactic structure of a given utterance in constructing phonological phrases. More specifically, there is a tendency to divide phrases into constituents of similar syllabic lengths. What is more, there is a strong binarity requirement on prosodic constituents, which is nevertheless overridden by the need to retain the integrity of the Object NP. Thus, an NP of the type panes de millo 'corn breads' will be phrased together as a whole rather than divided into two intonational pieces - a situation which is not necessarily warranted for the whole QP. Finally, Prieto, Estebas-Vilaplana, and Vanrell (2010) studied the pattern of tonal alignment with segmental material in Spanish and Catalan, demonstrating that prosodic structure plays an important role in speakers' lexical decisions in ambiguous contexts, and that it is correlated with segmental gestures. What is more, the study revealed an effect of prosody in offline word identification, which means that tonal patterns clearly influence speech perception. From the point of view of Broś' experiment, it is worth investigating the audio stimuli presented to the participants alongside participant productions to see whether input prosody could have affected the recorded outputs during task performance.

Coming back to our data, although no QP phrases were analysed by Prieto (2007) or Elordieta, Frota, and Vigário (2005), the different configurations of VPs, NPs, PPs and APs taken into account in these studies lead to the conclusion that the QP discussed above (cinco...) can either be phrased as a single constituent or with a boundary between the numeral and the 'prototypical' NP. We can thus imagine the following structures: $(\mathrm{He}$

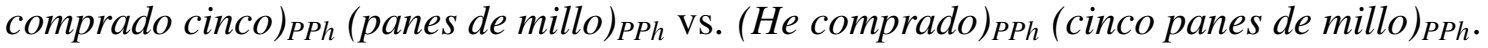
Acoustic data seem to corroborate this prediction: the preliminary analysis of phrase doublets produced by the same speaker with and without voicing at two different moments of the experiment shows slight differences in pitch (rise continuation vs. break). This might 
suggest differences in phrasing that could induce voicing or block it, even in the absence of pauses in the speech signal. ${ }^{11}$ We can imagine that, when the numeral is phrased separately, voicing is not promoted. Rather, domain strengthening (Cho, 2016; Fougeron and Keating, 1997) can ensue: stop gestures are reinforced, leaving a given segment less susceptible to voice spilling from the preceding vowel. Such an interpretation finds support in studies on the prosody-phonetics interface.

In a review paper, Cho (2016) discusses the ways in which prosodic structure modulates the phonetic realisation of phonological outputs, with a focus on boundary phenomena. In this model, prosody serves as an interface between phonological computation and actual pronunciation, and depends not only on segmental structure, but also on the intended meaning. Prosody's function is to delimit constituents and to group prosodic units together under appropriate nodes, as well as to mark prominence (e.g. head words). Thus, pitch movements mark the rhythm of the utterance. At the edges of prosodic constituents, lengthening and enhancement take place. These can take the form of phrase and boundary tones. Crucially, the mutual influence of phonetics and prosody is not limited to suprasegmental structures. Segments are also affected by this relationship (Cho, 2011; Fletcher, 2010). The central question of studies on the prosody-phonetics interface is how fine-grained phonetic detail is modulated during speech production at prosodic junctures. Here, the notion of domain-final lengthening (Byrd, 2000; Edwards, Beckman, and Fletcher, 1991), i.e. temporal and spatial expansion of the articulatory gestures, is of special interest. The second relevant term is domain-initial strengthening, or DIS. Typically, in post-boundary position, segments tend to be produced with a stronger articulation (Cho and Keating, 2001; Fougeron and Keating, 1997). This effect is a function of the level of the prosodic domain (the higher the prosodic constituent, the 'stronger' the articulation of the initial sound). Such strengthening has to do with the articulatory force and the need for the speaker to reset his/her respiratory cycle and therefore gestures corresponding to the articulation of the following sounds.

Recent studies have shown that several acoustic cues (e.g. VOT or amplitude) depend on boundary level/strength and on the putative speaker decisions taken in communicative situations (Cho, McQueen, and Cox, 2007). In stops, both closure duration and degree of constriction tend to be greater at the beginning of a bigger prosodic constituent (e.g. PPh or IP as opposed to PW). Undershoot (Lindblom, 1963) will be therefore more common at lower-level boundaries, whereas the articulatory targets of segments marking higher-level boundaries will be more easily attained. Note that in the case of Spanish, the variable distribution of spirantisation depending on the context can be explained in terms of prosody. According to the data provided by numerous researchers across the different dialects, spirantisation is the most advanced in word-internal intervocalic position ( $\sigma$ boundary), followed by phrase-level intervocalic position and post-consonantal contexts. Whereas voiced stops can be elided word-internally, it is forbidden at the beginning of a word (PW), regardless of speech rate and other factors. Following a pause, no spirantisation is allowed (DIS). ${ }^{12}$ Similar effects can be predicted in the case of underlyingly

$11 \quad$ Note that pauses are usually associated with IP boundaries and may be very short or inexistent between PPh or PW domains.

12 As for the production of stops, although no study parallel to Broś (to appear) has been conducted that would compare voicing degrees in different prosodic positions, interesting results have been obtained for English and Dutch in terms of glottal differences. Cho and 
voiceless stops. Voicing can be inhibited to some degree, and the related weakening markers, such as the degree and duration of constriction, may be affected. The lack of plosion, the presence of formants and the differing length of the stops in question reported earlier may result from the influence prosodic boundaries exert on articulation.

To conclude the discussion on prosody and its potential influence on voicing, it should be noted that the process does not seem to be affected or modulated by physical pauses. Rather, it may be sensitive to the differences in NP phrasing and the accompanying discrepancies in pitch. If, following this hypothesis, the voicing of the underlying voiceless non-continuants can be blocked by structural prosody considerations, it is also possible that elided phonological segments structurally mark prosodic boundaries. We can imagine that, in deletion blocking environments, as illustrated in (9), the underlying segmental and featural information is present, and there can also be an intention or a residual gestural configuration for the production of the non-continuant, which is nevertheless deleted. Instead of being completely erased, it marks its presence in structural terms: a root node with no melody remains in the phonology and marks the edge of a prosodic constituent. This is subsequently translated into blocking at the prosody-phonetics interface.

\section{Voicing and turbidity in Gran Canarian Spanish}

As argued in the previous sections, structural information must be retained beyond phonology, especially at the interface between the phonological and the phonetic components in order to account for variable voicing and for the blocking effect observed in Gran Canarian Spanish. Insight into the deep structure at the level of phonology only, analysed as containment (Prince and Smolensky, 1993), is insufficient in view of the phonetic data that dismiss post-vocalic voicing as a categorical process. The acoustic information gathered in the course of the phonetic study conducted by Broś (to appear) shows variability both in the rates of production and in the degrees of voicing. What is more, it also points to the role of prosody as a structural marker regulating speech. With these facts in mind, it is impossible to assume that only non-empty phonological structures are interpretable at the level of phonetics.

This idea is not new, as abstract phonological structures have always been phonetically interpretable and used as pronunciation cues in accordance with the principles of generative phonology. Syllable structure and other prosodic domains are assumed to be valid 'post-phonologically'. Since these are 'structural' or 'representational' elements rather than segmental data, other parts of phonology that can be analysed as a phonological framework or matrix on which featural/melodic and timing information is based must not be omitted. Thus, root nodes and other parts of underlying representational data have to be retained, whether attached to the data from other tiers or not. This has been referred to as 'the projected' vs. 'the pronounced', covert vs. overt structures, or 'tur-

Keating (2009) and Fougeron and Keating (1997) and others have shown that the VOT in English stops tends to be longer at phrase vs. word boundaries. Cho and McQueen (2005) report an opposite effect in Dutch, which they attribute to language-specific contrast enhancement principles. A similar study of the Spanish outputs might shed some light on this issue. 
bid' representations, e.g. by Goldrick (1998), Oostendorp (2006), Revithiadou (2007), and Trommer (2011) (among others). All of these approaches date back to the original proposal of Prince and Smolensky (1993) involving containment in the framework of Optimality Theory.

According to the original assumptions of the framework, whenever a segment or feature is absent from the output, it is represented as unparsed, i.e. not incorporated in the surface representation of the analysed sequence of sounds, but not erased completely. Building on this insight, Goldrick $(1998,2000)$ assumes turbidity for certain phonological representations. As argued by this author, input sound properties are projected, but not necessarily pronounced, and projection and pronunciation lines govern input-output relations. In OT, this involves a reformulation of certain constraints so that they reflect these association lines, and an introduction of a violable RECIPROCITY constraint that requires bidirectionality. Thus, the abstract structural relationship between the segments and their featural representations must be faithfully rendered in surface realisations, which are then subject to phonetic interpretation. This is typically illustrated in the form of arrows: a down arrow for projections and an up arrow for pronunciations.

Marc Oostendorp's (2006) Coloured Containment framework builds on the projected vs. the pronounced hypothesis put forward by Goldrick, and on the notion of Consistency of Exponence, according to which 'no changes in the exponence of a phonologically-specified morpheme are permitted' (McCarthy and Prince, 1993, 1995). The interpretation of this principle is based on a set of assumptions: a) GEN cannot affect the lexical specification of morphemes, b) epenthetic elements cannot be linked to underlying morphological structure, and c) deleted elements are interpreted as unparsed and unable to change a given morpheme's makeup. Crucially, Containment is assumed for all input-output relations, albeit in a revised version.

Revithiadou (2007) follows Goldrick and van Oostendorp in assuming Coloured Containment, which she deems superior to classical OT in that it gives phonology insight into the morphological affiliation of phonological elements. As a result, OT constraints can be formulated in a way that better 'controls the mapping between morphological structure and prosodic form' (ibid., p. 3). This 'structural' approach to phonological interactions is in line with the prosodic approach laid out in this paper. Underlying material, both segmental and structural (weight units and root nodes, feature matrices, etc.), is set out in the course of or following morpheme concatenation and then built upon by phonology. Since prosodic categories are erected in the phonological component based on a language-specific algorithm, via the interaction of relevant constraints, a mismatch between prosody and morphology can ensue. This can explain opacity effects at the morphology-phonology interface and, at the phrase level, also at the interface between morphophonology and syntax. At the same time, it must be remembered that prosodic structure is secondary to the input. In terms of containment/turbidity frameworks, this means that prosodic constituents are elements with no corresponding morphemic "colouring'.

Although the turbidity model was introduced and later used above all to solve representational problems related to autosegmental material accompanying segmental phonology, ${ }^{13}$ it can also be successfully used to account for segmental phenomena, such

13 Lugandan compensatory lengthening (Goldrick, 1998), stress shift in Greek (Revithiadou, 2007), spreading and reciprocity in vowel harmony (Finley, 2008), to name a few. 
as derived environment effects (Oostendorp, 2006) or opaque counterfeeding effects presented in this paper. As shown by the Gran Canarian Spanish data, covert material can exert an effect on surface structures, which is in line with Goldrick's original claim that 'the output of the grammar [may] contain unpronounced material which 'can' influence the surface - the portion of the output which is pronounced' (2000, p. 2). Furthermore, as rightly argued by Revithiadou (2007, p. 14), the representational distinction between the UR and the surface form cancels the need to refer to representational or structural elements such as association lines in constraint formulation, and at the same time allows for embracing containment in the sense of representing phonological deletion without the physical removal of any features from the input. Such a move is necessary to represent floating features and/or segments in the grammar, as well as underlying elements and 'intermediate forms' that influence surface realisations in a non-transparent manner. ${ }^{14}$

To account for the underapplication of voicing in deletion environments presented in Section 2, I propose a simplified version of the Turbidity/Containment model based on a parallel evaluation mechanism (no strata). Since the underlying material is present on the surface, no serialist approach is necessary - any opacity relation is rendered transparent. The framework assumes that alignment constraints govern the edges of constituents and, being violable, admit mismatches between morphological and prosodic domains. ${ }^{15}$

In the proposed model (see also Broś 2016a), OT constraints have slightly different formulations. MAX(Seg), for instance, reflects projection-pronunciation relations and obeys the Consistency of Exponence principle. Thus, whatever is 'deleted' is not removed from the representation, it is simply left unpronounced, i.e. lacks the pronunciation association line between the input and the output structure. Since nothing can be removed from the input, the deleted segment is projected but unpronounced, hence the representation is $\left[S_{\uparrow}\right]$ as opposed to a segment that is pronounced: $\left[S_{\uparrow \downarrow}\right]$. $\operatorname{MAX}(\operatorname{Seg})$ is violated in the former case. An epenthetic segment, by contrast, would have a reverse structure: unprojected, but pronounced: $\left[S_{\downarrow}\right]$. Such a structure would violate $\operatorname{DEP}(\operatorname{Seg}) .{ }^{16}$ Note that in both segment deletion and epenthesis it is root node reciprocity that is violated. The corresponding constraints can be therefore interpreted as phonological transparency guardians. The representation of the phonological outputs based on these principles should include association lines marking projection (input/morphological specification) and pronunciation (surface realisation resultant from the evaluation as per the constraint hierarchy) at

$14 \quad$ Note, however, that the non-transparency of the input-output mappings in the case of Gran Canarian Spanish has been moved to the phonology-phonetics interface. Given the phonetic status of voicing established in the previous sections, the phonological evaluation of deletion (and its effects on the neighbouring sounds) is rendered transparent. The opacity lies at the level of interpretation of phonological outputs in the phonetics. This is important for Spanish due to the fact that it admits resyllabification across word boundaries. Opacity effects caused by this operation in some dialects can be resolved to some extent with the use of turbid structures. I do not go into the details of this assumption as it goes beyond the scope of this paper. work, however, it would be possible to have an epenthetic segment that affects grammar, but which is left unpronounced later on. In such a case, the intermediate representation could reflect the appearance of such elements, but the final output would be devoid of them. 
the level of the root node. In other words, each root node can be both projected and pronounced, only pronounced or only projected, depending on the result of the evaluation, which is represented visually in the form of up and down arrows. This is exemplified based on the phrase pensar tonterías 'think about silly things'. Assuming word-final coda deletion, the phonological output form is as follows.

\section{Representation of the output pensar tonterías}

$$
\left(p_{\uparrow \downarrow} e_{\uparrow \downarrow} n_{\uparrow \downarrow}\right) \cdot\left(s_{\uparrow \downarrow} a_{\uparrow \downarrow} r_{\uparrow}\right) \cdot\left(t_{\uparrow \downarrow} o_{\uparrow \downarrow} n_{\uparrow \downarrow}\right) \cdot\left(t_{\uparrow \downarrow} e_{\uparrow \downarrow}\right) \cdot\left(r_{\uparrow \downarrow} \hat{1}_{\uparrow \downarrow}\right) \cdot\left(a_{\uparrow \downarrow} s_{\uparrow}\right)
$$

To simplify this structure, I propose that segments obeying reciprocity be represented directly in their melodic form (IPA symbol), and that deviants be accompanied by structural markers (arrows). This is shown in (14) below.

\section{Simplified representation of the output pensar tonterías}

$$
\text { (pen).(sar } \uparrow) .(t o n) .(t e) .(\text { rí}) .\left(_{\left(\mathrm{as}_{\uparrow}\right)}\right)
$$

Note that in the turbidity framework $\mathrm{MAX}(\mathrm{Seg})$ is reinterpreted as a general RECIPROCITY(Rt) constraint working in the familiar I $\rightarrow \mathrm{O}$ direction as in classical correspondence theory (McCarthy and Prince, 1995). The reverse relation is governed by the $\operatorname{DEP}(\mathrm{Seg})$ constraint.

\section{Definitions of MAX and DEP constraints under turbidity}

RECIPROCITY $\left(\mathrm{Rt}_{\text {Max }}\right)$ : assign a violation mark if the input (projected) root node is not incorporated in the output structure (pronounced)

$\operatorname{RECIPROCITY}\left(\mathrm{Rt}_{\text {Dep }}\right)$ : assign a violation mark if the output (pronounced) segment is not incorporated in the input structure (projected as a root node)

The evaluation of candidates generated based on the input structures is effected via the interaction between RECIPROCITY constraints and surface markedness constraints which govern the pronunciation of particular segments and autosegments. They are similar to Goldrick's (2000) PRONOUNCE constraints. In the case of coda deletion, the relevant markedness constraint is $\left.{ }^{*} \mathrm{C}\right] \mathrm{CODA}$, which states that consonants are not pronounced in coda position.

(16) *C]CODA: assign a violation mark for each pronounced coda segment.

The evaluation is provided in (17). ${ }^{17}$

17 In all evaluations, I ignore coda consonants other than continuants, which are the segments undergoing deletion in the dialect. Note, however, that the active role of the constraint $*$ C]CODA does not protect e.g. nasals (in the very word tonterías). I assume that nasal codas are licensed by homorganic onset segments as they do not appear in heterorganic contexts, and are hence retained thanks to other relevant constraints. The general $* \mathrm{C}$ ]CODA must be active in the dialect as word-final nasals debuccalise, and non- 


\section{Successful evaluation of pensar tonterías 'thinking about silly things'}

\begin{tabular}{|c|c|c|}
\hline /pensar tonterias/ & $*$ C]CODA & $\operatorname{REC}\left(\mathrm{Rt}_{\mathrm{Max}}\right)$ \\
\hline (pen).(sar).(ton).(te).(rí).(as) & $* * !$ & \\
\hline 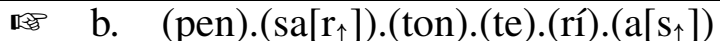 & & *** \\
\hline
\end{tabular}

In (17), reciprocity in the projected vs. pronounced material is sacrificed to obey a higherranked constraint, $\left.{ }^{*} \mathrm{C}\right] \mathrm{CODA}$. Thus, the ranking $\left.{ }^{*} \mathrm{C}\right] \mathrm{CODA} \gg \mathrm{REC}\left(\mathrm{Rt}_{\mathrm{Max}}\right)$ ensures that coda segments are deleted. Since the process is optional (coda segments are retained in careful speech), I assume variable ranking depending on the register. ${ }^{18}$ As for the $/ 1 /$, a high-ranked identity constraint prevents its elision at word edges. Note that the observed effect is PW-final. It might be therefore tempting to posit a constraint that refers directly to the right edge of the word in order to avoid deletion word-internally (e.g. in arte [ar.te] 'art'). Nevertheless, this is unnecessary for two reasons. First, at word edges, coda deletion interacts with resyllabification. If the word-final consonant can be resyllabified as an onset together with the following word-initial vowel, it does so and hence cannot be deleted. This is confirmed by native speakers' realisations, e.g. pensar en algo [pen.sa.re.yal.yo] 'think about something'. Second, the weakening of /s/ in word-internal position is driven by the same constraint as at word edges. Coda /s/ is debuccalised to [h]. Word-internal deletion is prevented by CONTIGUITY which prohibits morpheme-internal root node delinking. ${ }^{19}$

Although, as argued in the previous sections, there is no phonological voicing that would interact with deletion in Gran Canarian Spanish, spirantisation does apply alongside the latter process. This type of weakening is mandated by another markedness constraint, defined briefly below.

*[+cont][-cont, -nasal]: assign a violation mark for every non-continuant other than a nasal that is pronounced after a continuant sound. ${ }^{20}$

The above constraint interacts with identity constraints preventing feature changes, and with the $\mathrm{Rt}_{\mathrm{Max}}$ reciprocity constraint. The relevant feature here is [+/-continuant]. Note

continuant codas are either approximantised or dropped inside words and across word boundaries (e.g. libertad 'freedom', adquirir 'to acquire').

As noted by a reviewer, a Stochastic OT (Boersma and Hayes, 2001) solution might be considered in this case as the framework deals specifically with variation/optionality. For the time being, however, there are no quantitative data on the rate of occurrence of deletion in Canarian, hence I will leave this line of inquiry for future studies.

It is worth mentioning that infinitive+pronoun structures are also resistant to deletion despite there being a morpheme boundary between the two words, e.g. acusarlo 'to accuse $\mathrm{him} /$ her' or besarte 'to kiss you'. As these are clitic structures, they can serve as motivation for positing a constraint mandating contiguity in prosodic words (in this case, PW'). For other arguments supporting this constraint in Spanish and in Slavic languages, see Broś (2015) and Rubach (2011), respectively. Also, as noted by a reviewer, it is worth mentioning that the behaviour of final consonants vis à vis the proposed PW contiguity constraint may differ from language to language. In some dialects of Catalan, for instance, infinitival -r is deleted before a clitic (Artés Cuenca, 2016). 
that under the turbidity framework identity constraints must take a revised form. IDENT (cont), for instance, states that the feature [continuant] must be incorporated in the underlying/surface structure. Since structural relations go in two directions (from the input to the output and back), two featural reciprocity constraints must be used to formalise the correspondence between projection and pronunciation lines. I will use the general constraint formulation pattern established by Oostendorp (2008) and applied by TorresTamarit, Linke, and Vanrell (2017).

\section{Featural reciprocity constraints under turbidity (Torres-Tamarit et al. 2017)}

a. RECIPROCITY ${ }_{\mathrm{F}}^{\mathrm{r}}$ : assign a violation mark for every feature $F$ projected by a root node $r$ that is not pronounced by $r$.

b. RECIPROCITY $\mathrm{F}_{\mathrm{r}}$ : assign a violation mark for every feature $F$ pronounced by a root node $r$ that is not projected by $r$.

This makes a distinction between inserted and deleted features. In the case of voiced stops following continuant sounds in Gran Canarian Spanish, both RECIPROCITY ${ }^{\mathrm{r}}$ cont and RECIPROCITY ${ }^{\text {cont }}{ }_{\mathrm{r}}$ will be violated by an approximant output. Assuming binary features, the underlying [-continuant] specification is not pronounced, and the pronounced [+continuant] feature was not projected at the level of the input. To simplify the analysis, the two constraints can be collapsed into the general RECIPROCITY(cont), ${ }^{21}$ which must be ranked lower than the markedness constraint banning different specifications for continuancy in adjacent segments. Note that to ensure deletion, RECIPROCITY $\left(\mathrm{Rt}_{\text {Max }}\right)$ must be ranked low. Complete loss of voiced stops is avoided by the adherence to the high-ranked *C]CODA. Note that voiced stops are typically in the onset position, both post-vocalically and post-consonantally, hence their loss would be equivalent to a gratuitous violation of RECIPROCITY $\left(\mathrm{Rt}_{\text {Max }}\right)$. Also, high-ranked ONSET mandates saving consonants and (re)syllabifying them with the following vowel at all cost (icluding morphophonological misalignment). The tableau in (20) presents the evaluation of inputs presenting deletion and spirantisation, based on the example pensar de 'think about'.

\section{Successful evaluation of pensar de 'think about'}

\begin{tabular}{|c|c|c|c|c|}
\hline /pensar de/ & $\begin{array}{l}*[+ \text { cont }] \\
{[\text {-cont }, \text {-nasal }]}\end{array}$ & $* \mathrm{C}] \mathrm{CODA}$ & $\begin{array}{c}\mathrm{REC} \\
\text { (cont) }\end{array}$ & $\begin{array}{c}\mathrm{REC} \\
\left(\mathrm{Rt}_{\text {Max }}\right)\end{array}$ \\
\hline a. $\quad($ pen $) .\left(\mathrm{sa}\left[\mathrm{r}_{\uparrow}\right]\right) \cdot(\mathrm{de})$ & $* !$ & & & $*$ \\
\hline 䟚 b. $\quad$ (pen). $\left(\mathrm{sa}\left[\mathrm{r}_{\uparrow}\right]\right) \cdot\left(\partial_{\top} \mathrm{e}\right)$ & & & $*$ & $*$ \\
\hline
\end{tabular}

The representation of the structural relations within the root node's featural specification depending on the output, as per (20), is presented below.

$21 \quad$ An underspecified segment would violate RECIPROCITY ${ }^{\mathrm{r}}$ cont only, which is where the effect of the two versions of RECIPROCITY makes a difference. 


\section{Representation of output [d]}<smiles>[R]=[GeH]</smiles>

\section{Representation of output [ðָ]}

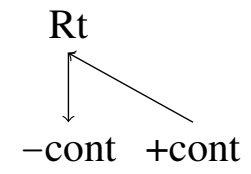

As demonstrated in (20), with the input /d/, a change into an approximant disobeys RECIPROCITY. The [-continuant] feature is projected, but not pronounced. Instead, the [+continuant] feature is realised on the surface, albeit without the corresponding projection line.

Note that in accordance with the principles of approximant distribution in the dialect, spirantisation applies regardless of consonant deletion. The tableau in (23) presents the output of pensar de as produced in slow, careful speech.

\section{Evaluation of pensar de 'think about' realised with no deletion}

\begin{tabular}{|c|c|c|c|c|}
\hline /pensar de/ & $\begin{array}{l}*[+ \text { cont }] \\
{[\text {-cont, }- \text { nasal }]}\end{array}$ & $\begin{array}{c}\mathrm{REC} \\
\left(\mathrm{Rt}_{\mathrm{Max}}\right)\end{array}$ & *C]CODA & $\begin{array}{c}\text { REC } \\
\text { (cont) }\end{array}$ \\
\hline a. $\quad$ (pen).(sar).(de) & $* !$ & & & \\
\hline b. $\quad$ (pen). $\left(\mathrm{sa}\left[\mathrm{r}_{\uparrow}\right]\right) \cdot\left(\mathrm{T}_{\mathrm{T}}\right)$ & & $* !$ & & * \\
\hline c. (pen).(sar).(ðe) & & & $*$ & $*$ \\
\hline
\end{tabular}

As demonstrated in the above tableaux, deletion and spirantisation operate at the level of phonology. The generated outputs are subsequently subject to phonetic implementation.

An important consequence of the above analysis and of the discussion provided in the previous sections should be emphasised at this point. Note that in Section 2 I pointed to the apparent chain shift effect visible on the surface due to the partial overlap of the contexts of voicing and spirantisation. In Sections 3 and 4, however, I argued that the phonetic evidence counters the assumption that the first process is categorical. Instead, it should be treated as an incipient change 'in the making' that has not been phonologised yet. Such a treatment of voicing solves the opacity problem because the apparent synchronic chain shift does not ensue at the level of phonological computation. ${ }^{22}$ Thus, the evaluation of non-continuants vis à vis deletion is rendered transparent in Gran Canarian Spanish, which should be considered an advantage of the framework set forth herein.

The activity of voicing at the level of phonetics requires an explanation. Given that structural information is crucial for the analysis of segmental changes under turbidity, the question is how it is retained and interpreted post-phonologically. One important assumption must be added. As noted by Oostendorp (2008), the Stray Erasure principle (Itô, 1986), which states that the phonetics interprets only parsed phonological material, needs to be reformulated. Since the material present at the level of the input and in the lexical representation of any given morpheme cannot be deleted, Oostendorp proposes that "[ $t]$ he phonetics only interprets features that stand in a pronunciation relation to a segment in the phonology" (2008, p. 9). Nevertheless, given the fact that the underlying presence of the deleted consonant in Gran Canarian Spanish exerts an influence on the phonetic imple-

$22 \quad$ For arguments against the existence of synchronic chain shifts, see e.g. Neasom (2016). 
mentation of phonological outputs, the latter definition is also too restrictive. Structural information must be transferred to phonetics. Therefore, I propose a revised formulation of Stray Erasure (24).

\section{Stray Erasure with Structural Tracing}

a. Melody: The phonetics only interprets features that stand in a pronunciation relation to a segment in the phonology.

b. Structure: The phonetics inherits structural traces from phonology, i.e. root node and boundary markers.

According to the above definition, prosodic information, as well as structural markers of empty melodic positions are available to phonetics and subject to interpretation in line with the articulatory restrictions and language-specific information beyond phonology. Thus, the output contains both melody (feature bundles) and simplified surface structure markers that may influence both articulation and perception. Gradient effects are the direct outcome of such information, combined with the neighbouring segmental data. In our case, phonetics receives the following structure. ${ }^{23}$

\section{Phonological output of pensar tonterías subject to phonetic interpretation}

$$
\left[\text { pensa }_{\uparrow} \text { tontería }_{\uparrow}\right]
$$

In view of the fact that, phonetically, voicing depends not only on the presence or absence of the preceding sound, but also on prosodic boundaries (see Section 4), the latter information must also be transposed to the articulation stage. In accordance with the turbidity framework set forth here, I propose that prosodic domain strength be based on the hierarchical structure erected in the phonological component and translated into a set of strength markers at the phonology-phonetics interface. The strength hierarchy is presented below.

\section{Prosodic strength categories interpretable in phonetics}

$$
\begin{aligned}
& \sigma=\mid 1 \\
& \sigma=\mid 2 \\
& \mathrm{PW}=\mid 3 \\
& \mathrm{PPh}=\mid 4 \\
& \mathrm{IP}=\mid 5
\end{aligned}
$$

23 The result of this proposal is similar to Oostendorp's analysis of incomplete devoicing and the way in which differences in the structural representation (and projection/pronunciation relations) in phonology translate into variable or incomplete devoicing of obstruents in a number of languages. The difference is that with the deletion cases presented in this paper, the discrepancy between surface representations is visible non-locally, i.e. in the segments following the deleted segment, and is hence projected indirectly, which cannot be expressed at the level of feature projection/pronunciation. 
The categories presented in (26) are both incremental and cumulative, in accordance with the studies concerning the acoustic and perceptual correlates of prosody. For instance, while the syllable is the weakest boundary, it grows in strength when it is stressed (strength $1+2=3$ ). When a stressed syllable, in turn, marks the end of an intonational unit, it receives a pitch accent, hence the status of a head word in an utterance. Prosodic boundaries mark structural or parsing information which is interpreted phonetically as a set of cues concerning the intonational contour (rises and falls, breaks and pauses, etc.). ${ }^{24}$

In this model, the output of the phrase pensar tonterías will therefore take the following form.

\section{Revised output of pensar tonterías subject to phonetic interpretation}

$$
\left[\operatorname{pen}_{\mid 1} \mathrm{sa}_{\uparrow|1| 2 \mid 3} \operatorname{ton}_{\mid 1} \text { te } \mathrm{rí}_{|1| 2} \mathrm{a}_{\uparrow|1| 3 \mid 4}\right]
$$

Such an interpretation of the structural information fed by phonology allows the grammar to account for speech variation. The relative differences in production between outputs dependent on prosody are modulated at the level of phonetics based on the strength markers, and not only segmental data. Thus, depending on prosodic parsing, two different surface markings of the sample sentence He comprado cinco panes de millo can be produced by the speaker in online speech processing. This is illustrated in (28).

\section{Surface structural markers in post-phonology}

$$
\begin{aligned}
& \text { a. }\left[\mathrm{e}_{\mid 1} \operatorname{kom}_{\mid 1} \operatorname{pra}_{|1| 2} \underset{\mathrm{T}}{\partial \mathrm{o}_{|1| 3 \mid 4}} \sin _{|1| 2} \mathrm{ko}_{|1| 3} \mathrm{pa}_{|1| 2} \operatorname{neh}_{|1| 3} \mathrm{de}_{\mid 1} \mathrm{mi}_{|1| 2} \mathrm{jo} \mathrm{o}_{|1| 3|4| 5}\right] \\
& \text { b. }\left[\mathrm{e}_{\mid 1} \operatorname{kom}_{\mid 1} \operatorname{pra}_{|1| 2} \underset{\mathrm{T}}{\partial \mathrm{o}_{|1| 3}} \operatorname{sig}_{|1| 2} \mathrm{ko} \mathrm{ko}_{|1| 3 \mid 4} \mathrm{pa}_{|1| 2} \operatorname{neh}_{|1| 3} \mathrm{de}_{\mid 1} \mathrm{mi}_{|1| 2} \mathrm{jo} \mathrm{o}_{|1| 3|4| 5}\right]
\end{aligned}
$$

In line with the above representations, an appropriate intonational contour will be computed and produced, together with the appropriate level of consonant deletion in compliance with the parsing data. As a result, we get gradient voicing and voicing inhibition due to domain-initial strengthening of the non-continuant following a strong prosodic boundary in (28b).

\section{Conclusions}

In this paper, I argued that covert structure should be recognised as an indispensable element of grammar that exerts influence on surface forms beyond the phonological component. What is more, embracing turbidity extended by structural representations that are erected in the phonology and further transposed into phonetic detail is a necessary step toward understanding the nature and laws governing variation in language change. Based on the phonetic data from the Gran Canarian variety of Spanish, I tried to elucidate the irregular behaviour of its consonants and demonstrate that categorical phonological phenomena can affect gradient processes which are typically believed to be influenced by

$24 \quad$ Pragmatic information corresponding to the intention of the speaker and other discursive factors is, naturally, another influencing factor governing prosody. I do not get into details concerning this part of communication as it goes beyond the scope of this paper. 
acoustic cues and articulatory principles only. It appears that the phonetics has insight into some parts of deeper structure. Admitting turbid grammar with structural tracing is therefore the correct path to follow in analysing phrase-level phenomena.

\section{References}

Artés Cuenca, Eduard. 2016. "The influence of phonology on inflection: The interplay between syllabification and lexical insertion in Pallarese Catalan". PhD thesis. Universitat Autònoma de Barcelona.

Baković, Eric. 1995. "Strong Onsets and Spanish Fortition”. In: MIT Working Papers in Linguistics 23, pp. 21-39.

Bermúdez-Otero, Ricardo. forthcoming. Stratal Optimality Theory. Ed. by Ricardo BermúdezOtero. Oxford: Oxford University Press.

Bloch, Bernard. 1941. "Phonemic overlapping". In: American Speech 16.4, pp. 278-284.

Boersma, Paul and Bruce Hayes. 2001. "Empirical tests of the gradual learning algorithm". In: Linguistic Inquiry 32, pp. 45-86.

Boersma, Paul and David Weenink. 2015. Praat: doing phonetics by computer [Computer program]. URL: http: / / www. praat.org/.

Broś, Karolina. to appear. "Gran Canarian Spanish non-continuant voicing: gradiency, sex differences and perceptual bias". Ms.

- 2015. Survival of the Fittest: Fricative Lenition in English and Spanish from the Perspective of Optimality Theory. Ed. by K. Broś. Cambridge: Cambridge Scholars Publishing.

- 2016a. "Stratum junctures and counterfeeding: Against the current formulation of cyclicity in Stratal OT". In: Proceedings of the Forty-Sixth Annual Meeting of the North East Linguistic Society. Ed. by Christopher Hammerly and Brandon Prickett. Vol. 1, pp. 157-170.

- 2016b. "Between phonology and morphosyntax: voicing and spirantization in the Spanish of Gran Canaria". In: Phonology, its Faces and Interfaces. Series: Sounds - Meaning - Communication. Frankfurt am Main: Peter Lang.

Browman, Catherine and Louis Goldstein. 1990. "Tiers in articulatory phonology, with some implications for casual speech". In: Papers in Laboratory Phonology. Ed. by John Kingston and Mary E. Beckman. Cambridge: Cambridge University Press, pp. 341-376.

Byrd, Dani. 2000. "Articulatory vowel lengthening and coordination at phrasal junctures". In: Phonetica 57, pp. 3-16.

Cabrera Abreu, Mercedes and Francisco Vizcanno Ortega. 2010. "Canarian Spanish Intonation." In: Transcription of Intonation of the Spanish Language. Ed. by Pilar Prieto and Paolo Roseano. Munich: Lincom Europa, pp. 87-122.

Cho, Taehong. 2011. "Laboratory phonology". In: The Continuum Companion to Phonology. Ed. by Nancy Kula, Bert Botma, and Kuniya Nasukawa. London/New York: Continuum, pp. 343-368.

- 2016. "Prosodic boundary strengthening in the phonetics-prosody interface". In: Language and Linguistics Compass 10(3), pp. 120-141. 
Cho, Taehong and Patricia Keating. 2001. "Articulatory and acoustic studies of domaininitial strengthening in Korean”. In: Journal of Phonetics 29, pp. 155-190.

- 2009. "Effects of initial position versus prominence in English". In: Journal of Phonetics 37, pp. 466-85.

Cho, Taehong and James M. McQueen. 2005. "Prosodic influences on consonant production in Dutch: Effects of prosodic boundaries, phrasal accent and lexical stress". In: Journal of Phonetics 33, pp. 121-157.

Cho, Taehong, James M. McQueen, and Ethan A. Cox. 2007. "Prosodically driven phonetic detail in speech processing: the case of domain-initial strengthening in English”. In: Journal of Phonetics 35.2, pp. 210-243.

Colina, Sonia. 1997. "Identity constraints and Spanish resyllabification”. In: Lingua 103, pp. 1-23.

Edwards, Jan E., Mary E. Beckman, and Janet Fletcher. 1991. "The articulatory kinematics of final lengthening". In: Journal of the Acoustical Society of America 89, pp. 369-82.

Elordieta, Gorka, Sonia Frota, and Marina Vigário. 2005. "Subjects, objects and intonational phrasing in Spanish and Portuguese". In: Studia Linguistica 59(2/3), pp. 110 143.

Finley, Sara. 2008. "Formal and Cognitive Restrictions on Vowel Harmony". Ph.D. thesis, Johns Hopkins University.

Fletcher, Janet. 2010. "The prosody of speech: timing and rhythm". In: The Handbook of Phonetic Sciences. Malden, MA \& Oxford: Wiley-Blackwell, pp. 523-602.

Fougeron, Cécile and Patricia Keating. 1997. "Articulatory strengthening at edges of prosodic domains". In: Journal of the Acoustical Society of America 106, pp. 372840.

Goldrick, Matt. 1998. "Optimal opacity: Covert structure in phonology.” Johns Hopkins University, NJ.

- 2000. "Turbid output representations and the unity of opacity". In: Proceedings of NELS 30. GLSA Publications, University of Massachusetts, pp. 231-245.

Gussenhoven, Carlos and Haike Jacobs. 2011. Understanding Phonology Handbook. Ed. by C. Gussenhoven and H. Jacobs. London: Routledge.

Hualde, José Ignacio. 2002. "Intonation in Spanish and the other Ibero-Romance languages". In: Romance philology and variation. Ed. by Caroline Wiltshire and Jaoquim Camps. Philadelphia \& Amsterdam: John Benjamins, pp. 101-115.

Hualde, José Ignacio, Antxon Olarrea, and Erin O'Rourke. 2012. The Handbook of Hispanic Linguistics. Ed. by José Ignacio Hualde, Antxon Olarrea, and Erin O'Rourke. Oxford: Wiley-Blackwell.

Itô, Junko. 1986. "Syllable theory in prosodic phonology". Ph.D. thesis, University of Massachusetts, Amherst.

Johnson, Keith. 1997. Acoustic and Auditory Phonetics. Ed. by K. Johnson. Malden, MA \& Oxford: Wiley-Blackwell.

Kaisse, Ellen. 1999. "Resyllabification precedes all segmental rules: Evidence from Argentinian”. In: Formal Perspectives on Romance Linguistics: Selected Papers from the 28th Linguistic Symposium on Romance Languages. Ed. by J.M. Authier, B.E. Bullock, and L.A. Reed. Amsterdam: John Benjamins, pp. 197-210. 
Labov, William. 1990. "The intersection of sex and social class in the course of linguistic change". In: Language Variation and Change 2, pp. 205-254.

Lindblom, Bjorn. 1963. "Spectrographic study of vowel reduction". In: Journal of the Acoustical Society of America 35, pp. 1773-1781.

Lipski, John. 1996. El español de América. Ed. by J. Lipski. Madrid: Cátedra.

Mascaró, Joan. 1991. "Iberian spirantization and continuant spreading”. In: Catalan Working Papers in Linguistics 1, pp. 167-179.

McCarthy, John. 2008. "Gradual path to cluster simplification”. In: Phonology 25, pp. 271319.

McCarthy, John and Alan Prince. 1993. "Prosodic Morphology I: Constraint Interaction and Satisfaction". Ms., University of Massachusetts, Amherst, and Rutgers University.

- $\quad$ 1995. "Faithfulness and reduplicative identity". In: Papers in Optimality Theory. Ed. by Jill N. Beckman, Laura Walsh Dickey, and Suzanne Urbanczyk. GLSA Publications, University of Massachusetts, pp. 249-384.

Neasom, Nicholas. 2016. "Against Synchronic Chain Shifting”. Ph.D. thesis, University College London.

Nespor, Marina and Irene Vogel. 1986. Prosodic Phonology. Ed. by M. Nespor and I. Vogel. Dordrecht: Foris.

Nibert, Holly J. 2000. "Phonetic and phonological evidence for intermediate phrasing in Spanish intonation". Ph.D. thesis, University of Illinois at Urbana-Champaign.

Oftedal, Magne. 1985. Lenition in Celtic and in Insular Spanish. Universitetsforlaget Oslo.

Ohala, John J. 1983. "The origin of sound patterns in vocal tract constraints". In: The Production of Speech. Ed. by P.F. MacNeilage. London: Springer-Verlag, pp. 189216.

Oostendorp, Marc van. 2006. "Theory of Morphosyntactic Colours". Meertens Institute, Amsterdam.

- 2008. "Incomplete devoicing in formal phonology". In: Lingua 118(9), pp. 13621374.

Prieto, Pilar. 2007. "Phonological phrasing in Spanish". In: Optimality-Theoretic Studies in Spanish Phonology. John Benjamins.

Prieto, Pilar, Eva Estebas-Vilaplana, and María del Mar Vanrell. 2010. "The relevance of prosodic structure in tonal articulation: Edge effects at the prosodic word level in Catalan and Spanish". In: Journal of Phonetics 38, pp. 687-705.

Prince, Alan and Paul Smolensky. 1993. "Optimality Theory: Constraint Interaction in Generative Grammar." Ms., published in 2004 by Rutgers University Center for Cognitive Science.

Quilis, Antonio. 1993. Tratado de fonología y fonética españolas. Ed. by A. Quilis. Madrid: Gredos.

Revithiadou, Anthi. 2007. "Colored Turbid accents and Containment: A case study from lexical stress". In: Freedom of Analysis? Ed. by Sylvia Blaho, Patrik Bye, and Martin Krämer. Berlin: Mouton de Gruyter, pp. 149-174.

Rubach, Jerzy. 2011. "Syllabic repairs in Macedonian”. In: Lingua 121, pp. 237-268.

Selkirk, Elizabeth. 1986. "On derived domains in sentence phonology". In: Phonology Yearbook 3, pp. 371-405. 
Torres-Tamarit, Francesc, Katherin Linke, and María del Mar Vanrell. 2017. "Opacity in Campidanian Sardinian metaphony". In: Natural Language and Linguistic Theory 35(2), pp. 549-576.

Trommer, Jochen. 2011. "Phonological Aspects of Western-Nilotic Mutation Morphology". Habilitation thesis, University of Leipzig.

Wiltshire, Caroline. 2002. "Variation in Spanish aspiration and prosodic boundary constraints". In: Current Issues in Romance Languages: Selected Papers from the 29th Linguistic Symposium on Romance Languages. Ed. by T. Satterfield, Ch. Tortora, and D. Cresti. Amsterdam: John Benjamins, pp. 375-389. 
